\title{
Study on the Innovative Fusion of Retro Elements and Modern Fashion
}

\author{
Changmei Chen \\ Guangdong University of Science\& Technology, Dongguan, Guangdong, China, 523083
}

Keywords: retro elements; fashion design; modern fashion

\begin{abstract}
The development and renewal of modern fashion come from retro elements. Fashion design is very malleable and operational. Numerous retro trends affect the inspiration of modern designers, and "retro" has become the ubiquitous imprint of modern apparel design. It is an eternal theme of the design concept of clothing to introduce new ideas and cycle. As Roland put it: "Every new fashion is a subversion of previous fashion oppression." Fashion is advancing in the process of self-subversion and re-creation ${ }^{[1]}$. This paper summarizes the design elements of "retro" from Chinese traditional culture, at the same time, combined with the "old elements" of the Western Renaissance, and provides the classical design concept for modern dress design. From the region and the times, it explores and analyzes the expression of retroism in modern dress design, and finds historical and aesthetic basis for the retro design concept of modern dress design.
\end{abstract}

\section{Introduction}

In recent years, the Chinese retro elements have been widely used by the Chinese and foreign fashion designers, and even western fashion designers have succeeded in digging the ancient oriental and mysterious culture. In China, traditional Chinese retro elements have become the "angels and demons" in the hands of local costume designers. On the one hand, designers are trying to make new appearances while playing with concepts, but they sigh about the exquisite creativity that lags behind that of the Western design community ${ }^{[2]}$. On the other hand, they have struggled to combine the vast national culture with fashion. There are intricate connections between retro elements and modern fashion, and how to balance the relationship between the two is a very difficult thing. This article is studying the delicate relationship between them.

\section{The Basic Elements of Vintage Elements and Modern Fashion}

\subsection{Retro elements}

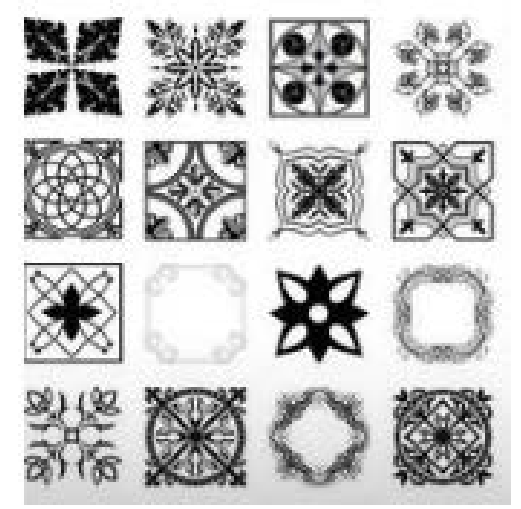

Figure 1 Retro Elements

In the field of clothing, retro is used to describe the retro elements in clothing. We can define all the necessary elements and basic units that are included in the old fashion style and used to create new styles as retro elements. However, the definition of "retro" is whether to enter the nostalgic elements in the design or directly The old design elements have always been difficult to define. The attribution of this "old" and retro elements is equally difficult to define: whether it was the beginning of Western 
Renaissance, or the thought system from ancient times to the design concept of the Tang and Song Dynasties, modern humanistic interest. Once the retro elements appear, they can always feel its unique visual impact. To a certain extent, retroism is a combination of traditional design language and modern design techniques. People can not completely Cutting off traditions and the inextricable emotions of history are the root causes of retroism ${ }^{[3]}$. The following picture shows the retro elements often appearing in the costume design. It is very common whether the design or sewing is tailored.

\subsection{Modern fashion}

Fashion is the style of life that was pioneered by a few people in a specific period of time and later advocated and imitated by the general public. Simply put, as the name suggests, fashion is the addition of "time" and "advocating". In this extremely simplified sense, fashion is the life that some people admire in a short time. This fashion involves all aspects of life, such as dress, diet, behavior, living, and even emotional expression and thinking. Many people will compare fashion with fashion, but this is not the case. Simply put, fashion can be popular, but the scope is very limited. If it is popular, does it still have a sense of fashion? The pursuit of fashion is an "art." Mimicking and conforming is only a "primary phase," and its state of mind is to extract the essence and true meaning from the wave of fashion in order to enrich its aesthetic and taste and create its own. Beautiful "template". The pursuit of fashion is not driven by passive pursuit but by sensible and skilled driving. In short, fashion is an all-encompassing concept. Its tentacles go deep into all aspects of life. People have been arguing about it all the time. In general, however, fashion brings people a pleasant mood and elegance, pure and extraordinary feelings, giving people different temperaments and charms, reflecting extraordinary taste of life, exquisite and revealing personality. At the same time, we are also aware that the pursuit of fashion by mankind has contributed to a better life for mankind. Figure 2 below is a representative form of modern fashion in the field of fashion design.

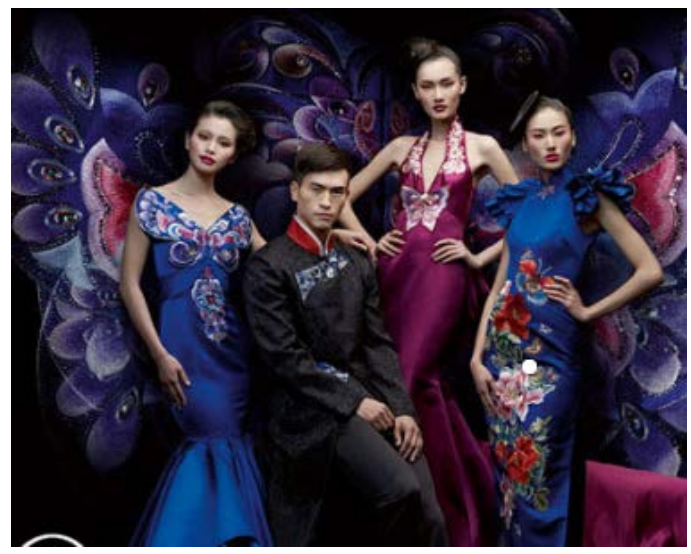

Figure 2 Modern Fashion in Fashion Design

\section{Causes of Vintage Elements of Clothing}

It is generally believed that the retro of clothing and other arts is often influenced by all kinds of artistic thoughts in the world. The Renaissance often plays an important role in them. The Renaissance is not simply a reproduction of classical culture, but is based on the promotion, combined with modern Elements constitute a new artistic language. Retro is a form. The diversification of art will inevitably create the conditions for the return of classical art. Historical development today, new things are emerging in an endless stream, people appear to be aesthetically fatigued by the emergence of common new things ${ }^{[4]}$. People begin to miss Past memories and things. The main factors that are generated by retroism are nostalgic thoughts. Nostalgia provides more figurative themes and emotional references for retro designs, but at the same time, it gives the design freedom because of the alienation of space and time. degree. 


\section{The Fashion of Retro Elements and Modern Fashion}

\subsection{The influence of Chinese retro elements on modern fashion}

Chinese style is a fashion style that has emerged in the fashion and art world in recent years. It is a nostalgic trend of oriental civilization from the Southeast Asia to European and American countries. The main features of Chinese style are elegant styling, exquisite workmanship, clever lines, and color. Ancient style. Patterns generally use dragon, phoenix, flowers, birds, calligraphy and other topics, the color is generally used strong red, elegant golden, deep blue, pure green and other highly saturated colors. Chinese style elements and modern The combination of popular elements of clothing can often produce unexpected or novel and unique clothing effects. For example, the combination of traditional red and black and popular high-waist and mouth-washing details can make Chinese-style clothes have a new trend of popular change. The "blue and white porcelain" is combined with popular fabric elements, blooming elements, and chic style elements, resulting in a simple and stylish effect. At present, many brands in China have been exploring Chinese fashion apparel, but the scale is very small and limited. In some costumes, the Chinese style fashion apparel is based on Chinese elements. It is based on Chinese culture and Oriental culture, and combines fashion and Chinese elements. Together, to adapt to global economic trends ethnic fashion, its unique cultural charm and personality will get the favor of the world.

\subsection{The influence of western vintage elements on modern fashion}

There are currently two major Western retroisms. The first was born in the late 9th century and early 20th century. At that time, with the rise of feminism and the rise of oriental culture, Europe brought new fashion. Traditional Japanese prints, kimono collars, Chinese cheongsams, Indian sari Full of exoticism. Ms. Chanel pioneered the pioneering of feminist clothing. It has a very important significance in the history of the world fashion. The design of Chanel began with the hat. Afterwards, she designed a sweater and a straight skirt. Woolen suits, small black dresses are called the classic fashion industry ${ }^{[5]}$. The second vintage was born in the $1960 \mathrm{~s}$, and liberalism became the mainstream style at that time. The hippies who pursued freedom pursued the ideal spiritual home, dressed in costumes that imitated Native American Indians. They may not even be hippies with absurd image symbols. And features. Will become the embryonic form of today's retro trend, but they are undoubtedly added more spiritual content for the retro, making this way of dressing invisible increasingly growing and accepted by the world. 2012 autumn and winter Paris High Fashion Week is a retro season, the innumerable design styles in the Western retro style followed, and countless retro influences inspired the designers: Romantic styles such as Baroque and Rococo add some fashionable dramatic elements and gorgeous charm to the costume; elegant blending Style offers a lot of fresh inspiration.

\subsection{The perfect blend of retro elements and modern fashion.}

Combining traditional Chinese elements with Western design elements, it is easy to achieve a prominent effect that shines brightly. China's "blue and white porcelain" was applied to western evening dresses, and its effect was refreshing. Cheongsam was made in the first half of the 20th century. The dress designers of the Republic of China refer to the Manchu women's traditional flag dresses and Western-western cut-out designs. The Qing Dynasty flag cuts have always been linear and does not reflect the figure of the female figure. The improved cheongsam tightened. The waist and the two sides of the slit further highlight the curvaceous beauty of women. It is an oriental and western culture. It is in the eyes of Westerners that the cheongsam has the symbolic significance of the Chinese women's dress culture. Fan Bingbing, the designer of the "Lucky Cloud of the East" by Lawrence The most important feature is the combination of Chinese and Western styles. It is fully westernized and three-dimensionally cut. The design elements are extremely classical and oriental. There are two dragons leaping high on the robes, and the wavy waves are embroidered on the feet of the mop. The waves are full of turbulent waves and there is a meaning of "Elevation of Ages". Between the dragons, the auspicious patterns embroidered with colorful moires symbolize the signs of auspiciousness. For 
thousands of years, the dragon has become a kind of The cohesion and accumulation of the Chinese culture has become a symbol of China. Fan Bingbing has demonstrated the beautiful Oriental charm to the world through Cannes's international stage ${ }^{[6]}$. The heritage of Chinese traditional culture and the spirit and temperament of Western liberal culture have created such a beautiful myth. Creator.

For the perfect blend of retro elements and modern fashion, I have to mention that in January this year, Wang Yuan Studios exposed a set of photos on Weibo. In the photo, Wang Yuan wears a five-pointed star pad shoulder suit, stylish and retro. Look carefully at the clothes in the picture. Retro pentagram elements make this dress a strong sense of the times. The tightening of the cuffs and hem enhances the fashion sense of this dress.

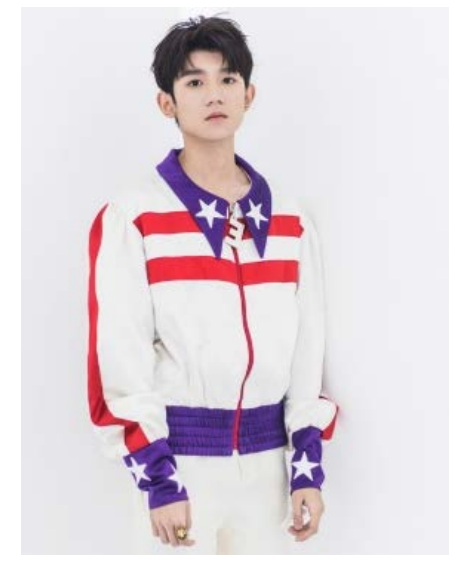

Figure 3 Pentagram shoulder pad set

\section{Conclusion}

History and culture leave us with eternal wealth. Vintage elements show more vitality after the integration of modern clothing design: With the continuous emergence and integration of new retro concepts and new elements, people will create more. Emerging fashion. As Ms. Chanel said, "fashion is dying, but style is forever!" The elements represented and represented in the retro elements are the traditional arts and traditional cultures of our country and are valuable treasures inherited from the development of ancient Chinese art. Modern fashion is a product of the progress of the times and is also the pursuit of spiritual fashion. The combination of the two is a collision of spiritual civilization and is of great research value.

\section{References}

[1] Qin Lina.A historic leap in the history of Chinese costumes[M]. Nanjing: Southeast University Press,2011(7):255.

[2] Lu Yanmei. Artistic Features of Women's Costumes in the Tang Dynasty[J]. Journal of Hebei University Thesis,2015(9):210.

[3] Wang Qunyu. The fusion of retro elements and modern fashion[M]. Nanjing: Southeast University Press,2016(4):43.

[4] Yu Fang; Striped Costume Design and Composition Art[J]; Journal of Huizhou University (Social Science Edition);2012-01

[5] Ye Hui, Yao Guizhen; Analysis of Retro Elements in Fashion Design[J]; Shandong Textile Economy; 2012,10

[6] Jingjing Li. The Application of Retro Elements in Fashion Design[J], Education Review, 2015(4):40. 